\title{
PENGARUH LAYANAN BIMBINGAN KELOMPOK TEKNIK DISKUSI TERHADAP KEMAMPUAN KOMUNIKASI INTERPERSONAL SISWA KELAS X SMAN 3 KOTA KEDIRI TAHUN AJARAN 2016/2017
}

\author{
Ima Yusnia Anita Sari, Atrup, dan Nora Yuniar Setyaputri \\ Universitas Nusantara PGRI Kediri \\ e-mail: yusniaima@gmail.com
}

\begin{abstract}
Abstrak: Penelitian ini dilatarbelakangi dari hasil pengamatan ketika melakukan Praktik Pengalaman Lapangan (PPL 2), tidak sedikit siswa yang merasa kesulitan dalam bergaul dan berkomunikasi dengan temannya meskipun dalam satu kelas, kurang adanya keterbukaan dalam menyampaikan pendapat, dan kurang adanya penghargaan terhadap pendapat teman lain. Hal ini menunjukkan kurangnya kemampuan komunikasi interpersonal siswa di SMAN 3 Kota Kediri. Tujuan dari penelitian ini adalah untuk mengetahui pengaruh layanan bimbingan kelompok teknik diskusi terhadap kemampuan komunikasi interpersonal siswa kelas X SMAN 3 Kota Kediri Tahun Ajaran 2016/ 2017. Penelitian ini menggunakan teknik kuantitatif dengan teknik penelitian pre-eksperimental designs dengan bentuk one-group pretest-posttest, dan sampel yang digunakan dalam penelitian ini adalah 32 siswa dari populasi 200 siswa pada kelas X di SMAN 3 Kota Kediri. Instrumen penelitian ini menggunakan skala psikologi. Data penelitian dianalisis dengan menggunakan analisis data statistik. Pelaksanaan bimbingan kelompok dengan menggunakan teknik diskusi di SMAN 3 Kota Kediri yang dilakukan peneliti kurang maksimal karena situasi dan kondisi yang tidak kondusif. Kemampuan komunikasi interpersonal siswa sebagian besar sudah baik, namun masih ada beberapa yang perlu ditingkatkan. Berdasarkan hasil perhitungan dapat diketahui bahwa nilai $p$-value $(0,000)$ $<\alpha 0,05$, maka $\mathrm{H}_{0}$ ditolak, $\mathrm{H}_{1}$ diterima, yaitu layanan bimbingan kelompok teknik diskusi berpengaruh terhadap kemampuan komunikasi interpersonal siswa kelas X SMAN 3 Kota Kediri. Berdasarkan simpulan dari penelitian ini, jika penelitian dapat terarah dengan baik dan dalam situasi yang kondusif, maka akan memberikan hasil yang optimal. Sehingga menurut hasil penelitian ini, bimbingan kelompok teknik diskusi memberikan pengaruh terhadap kemampuan komunikasi interpersonal siswa kelas X di SMAN 3 Kota Kediri. Dengan demikian, saran yang dapat diberikan yaitu hendaknya kegiatan diskusi dilakukan dengan sebaik dan sekreatif mungkin agar maksud dan tujuan diskusi dapat tercapai.
\end{abstract}

Kata Kunci: bimbingan kelompok, teknik diskusi, komunikasi interpersonal

\begin{abstract}
This research is based on observation when doing Field Experience Practice (PPL 2), not a few students who feel difficulty in socializing and communicating with their friends even though in one class, lack of openness in expressing opinion, and lack of appreciation to opinion of other friend. This shows the lack of interpersonal communication skills of students in SMAN 3 Kota Kediri. The purpose of this study is to determine the influence of guidance services group discussion techniques on interpersonal communication skills of students of class X SMAN 3 Kediri City Year Teaching 2016/2017. This research uses quantitative technique with pre-experimental designs technique with one-group pretest-posttest, and the sample used in this research is 32 students from population 200 students in class X in SMAN 3 Kediri City. The instrument of this study using psychological scale. Research data were analyzed by using statistical data analysis. The implementation of group guidance by using the discussion technique at SMAN 3 Kediri City conducted by researchers less than the maximum because of the situation and conditions that are not conducive. Interpersonal communication skills of students are mostly good, but there are still some that need to be improved. Based on the calculation results can be seen that the value of p-value $(0,000)$ $<\alpha 0.05$, then $H_{0}$ rejected, $H_{1}$ diterima, namely guidance services group discussion techniques have an effect on interpersonal communication skills of grade X SMAN 3 Kediri. Based on the conclu-
\end{abstract}


sions of this study, if research can be well directed and in a conducive situation, it will provide optimal results. So according to the results of this study, guidance group discussion techniques give influence to interpersonal communication skills of students of class X in SMAN 3 Kota Kediri. Thus, suggestions that can be given that the discussion should be done as well and as creative as possible so that the purpose and purpose of the discussion can be achieved.

Keywords: group guidance, discussion technique, interpersonal communication

\section{PENDAHULUAN}

Kehidupan masa remaja sangat menarik untuk dibicarakan dikarenakan kompleksnya permasalahan yang ada di dalamnya. Pada masa ini merupakan masa peralihan, di mana masa peralihan banyak menimbulkan kesulitan dalam penyesuaian terhadap dirinya maupun terhadap lingkungan sosialnya. Siswa SMA termasuk ke dalam fase remaja. Masa remaja merupakan sebuah periode dalam kehidupan manusia yang batasan usia maupun peranannya seringkali tidak terlalu jelas. Hal ini menunjukkan bahwa siswa SMA perlu diberi bekal sehingga dapat berkembang dengan baik.

Menurut Desmita (dalam Ramadan, 2013) mengemukakan tentang rentang usia masa remaja dibedakan menjadi tiga, yaitu usia 12-15 tahun merupakan masa remaja awal, 15-18 tahun merupakan masa remaja pertengahan dan 1821 tahun merupakan masa remaja akhir. Hurlock (dalam Ramadan, 2013) membagi masa remaja menjadi dua, yaitu masa remaja awal dari umur 13-16 atau 17 tahun, dan masa remaja akhir bermula dari usia 16 atau 17 tahun sampai 18 tahun yaitu usia matang secara hukum.

Berkaitan dengan hubungan sosial pada remaja, hampir seluruh waktu yang digunakan remaja adalah berinteraksi dengan lingkungan sosialnya, baik dengan orang tua, saudara, guru, teman, dan sebagainya. Remaja cenderung bergabung dan berinteraksi dengan kelompok sosialnya untuk mengembangkan keterampilan sosialnya. Ada beberapa tugas perkembangan remaja di antaranya yaitu mengembangkan keterampilan komunikasi interpersonal dan bergaul dengan teman sebaya atau orang lain baik secara individual maupun kelompok. Hal ini merupakan aspek yang terpenting dalam kehidupan karena setiap orang tidak akan lepas dari kegiatan komunikasi dan interaksi dengan orang lain. Komunikasi penting terhadap penciptaan konsep diri, aktualisasi diri untuk kelangsungan hidup, memperoleh kebahagiaan, dan terhindar dari tekanan dan ketegangan.

Selain itu, tugas perkembangan pada masa remaja adalah mencapai keberhasilan baru dan hubungan yang lebih matang dengan usia sebaya dari pria dan wanita, belajar secara sosial berperan dan berperilaku sebagai pria dan wanita, menginginkan dan mencapai perilaku tanggung jawab sosial, mengambil nilai-nilai dari masyarakat (Utomo, 2014). Dengan adanya tugas perkembangan yang telah disebutkan, maka sebagai remaja mereka berusaha untuk dapat memenuhinya. Untuk mewujudkan hal itu, dibutuhkan keterampilan dalam berkomunikasi khususnya komunikasi interpersonal agar hubungan sosial remaja bisa terpenuhi dengan baik.

Komunikasi interpersonal adalah komunikasi yang dilakukan kepada pihak lain untuk mendapatkan umpan balik, baik secara langsung (face to face) maupun dengan media.

Menurut Devito (dalam Aminudin, 2012: 15), komunikasi interpersonal adalah penyampaian pesan oleh satu orang serta penerimaan pesan oleh orang lain atau sekelompok kecil orang, dengan berbagai dampaknya serta dengan peluang untuk memberikan umpan balik segera. 
Elkid (dalam Mardiyati, 2011) menjelaskan bahwa pemikiran remaja berkembang dibandingkan dengan pemikiran anak usia sekolah, namun dalam kelabilan perkembangan remaja masih belum matang hal ini ditunjukkan dengan ketidakmatangan pemikiran yang disebut dengan egosentrisme remaja. Egosentrisme membuat remaja merasa bahwa tidak seorang pun dapat memahami isi hatinya, sebagai bagian dari upaya untuk mempertahankan perasaan tersebut remaja sering mengarang cerita tentang dirinya dengan penuh fantasi. Piaget (dalam Mardiyati, 2011) menjelaskan bahwa interaksi dengan teman sebaya dapat membantu remaja menguji pemikirannya, menerima umpan balik dan melihat orang lain mengatasi masalah.

Berdasarkan gejala tersebut maka salah satu layanan bimbingan dan konseling yang efektif untuk mengentaskan permasalahan siswa tersebut adalah dengan memberikan layanan bimbingan kelompok kepada siswa yang bermasalah dalam komunikasi interpersonalnya. Selain menggunakan strategi kegiatan kelompok, upaya meningkatkan komunikasi interpersonal juga dapat dilaksanakan dengan metode diskusi kelompok.

Alasan teknik diskusi dipilih menjadi teknik dalam pemberian layanan bimbingan kelompok ini adalah karena diskusi kelompok pada hakikatnya adalah kerjasama dalam mengumpulkan dan tukar-menukar pengalaman serta gagasan. Melalui diskusi, siswa dibina memperhatikan kepentingan orang lain, menghargai pendapat orang lain, dan menerima keputusan bersama. Melalui diskusi kelompok ini, peneliti dapat mendorong siswa untuk melatih kemampuan berpendapat menyatakan gagasan, perasaan, serta meningkatkan kepercayaan dirinya sehingga siswa nantinya dapat berkomunikasi antarpribadi secara lebih baik lagi di lingkungan sosial yang lebih luas. Menurut Yamin (dalam Mardiyati,
2011) bahwa teknik diskusi merupakan bentuk bimbingan belajar yang memberikan kesempatan semua siswa untuk berlatih berbicara secara terarah.

Sedangkan menurut Romlah (2001: 90) keuntungan-keuntungan dari teknik diskusi adalah sebagai berikut.

1. Membuat anggota kelompok lebih aktif karena tiap anggota mendapat kesempatan untuk berbicara dan memberi sumbangan pada kelompok.

2. Anggota kelompok dapat saling bertukar pengalaman, pikiran, perasaan, dan nilai-nilai, yang akan membuat persoalan yang dibicarakan menjadi lebih jelas.

3. Anggota kelompok belajar mendengarkan dengan baik apa yang dikatakan anggota kelompok yang lain.

4. Dapat meningkatkan pengertian terhadap diri sendiri dan pengertian terhadap orang lain. Melalui balikan yang diberikan anggota lain, terutama di dalam diskusi kelompok kecil, masing-masing anggota dapat melihat dirinya dengan lebih mendalam.

5. Memberi kesempatan pada anggota untuk belajar menjadi pemimpin, baik dengan menjadi pemimpin kelompok maupun dengan mengamati perilaku pimpinan kelompok.

Oleh karena itu, teknik diskusi sangat tepat digunakan dalam meningkatkan komunikasi interpersonal siswa. Teknik diskusi melatih siswa untuk berbicara, berpendapat secara terarah di depan kelompoknya dan melatih siswa menghargai orang lain yang sedang berpendapat. Diskusi tepat digunakan pada siswa yang mengalami kesulitan dalam berpendapat, mengungkapkan pendapat dan menanggapi pendapat orang lain. Diskusi merupakan salah satu cara yang digunakan dalam proses belajar mengajar yang melatih siswa untuk mampu dan berani berpendapat di 
dalam kelas. Di samping melatih siswa agar mampu dan berani berpendapat di dalam kelas, diskusi juga mengembangkan sikap sosial siswa karena di dalam diskusi siswa berhadapan dengan teman sebaya yang berbeda sifat dan karakternya.

Dalam praktiknya, diskusi kelompok memberikan sumbangan yang berharga terhadap belajar siswa menurut Jannah (2014), antara lain membantu siswa untuk tiba pada pengambilan keputusan yang lebih baik daripada memutuskan sendiri, siswa tidak terjebak kepada jalan pemikiran sendiri yang kadang-kadang salah, penuh prasangka, dan sempit. Sedangkan kelebihan dari teknik diskusi kelompok menurut Jannah (2014) adalah suasana kelas lebih hidup sebab siswa mengarahkan perhatian atau pikirannya kepada masalah yang sedang didiskusikan, rasa sosial mereka dapat dikembangkan karena dapat saling membantu dalam memecahkan masalah dan mendorong rasa kesatuan, memperluas pandangan, dan memberi kemungkinan untuk saling mengemukakan pendapat.

Penelitian tentang komunikasi interpersonal juga dilakukan oleh Sulistyanto (2014) dengan judul "Upaya Meningkatkan Komunikasi Antarpribadi Melalui Layanan Penguasaan Konten dengan Metode Kegiatan Kelompok dan Diskusi Kelompok Pada Siswa Kelas VIII F SMP Negeri 5 Semarang Tahun Ajaran 2013/2014”. Penelitian tersebut membuktikan bahwa komunikasi interpersonal dapat ditingkatkan melalui layanan penguasaan konten dengan metode kegiatan kelompok dan diskusi kelompok. Hal ini menjadi dorongan bagi siswa untuk bisa berinteraksi dengan orang lain dan unsur utama dalam interaksi adalah melalui komunikasi. Menurut penelitian Sari (2008) dengan judul "Efektivitas Metode Diskusi dalam Pembelajaran Biologi Kelas X MA Uswatun Hasanah Semarang" bahwa metode diskusi efektif untuk meningkatkan hasil belajar dan prestasi belajar siswa kelas $\mathrm{X}$ khususnya mata pelajaran biologi.

Penelitian lain yaitu penelitian yang dilakukan oleh Mardiyati (2011) dengan judul "Bimbingan Belajar Teknik Diskusi untuk Meningkatkan Keberanian Mengemukakan Pendapat di Dalam Kelas" yang hasilnya adalah bahwa bimbingan belajar teknik diskusi efektif meningkatkan keberanian mengemukakan pendapat di dalam kelas pada siswa kelas VII A SMPN 20 Surakarta Tahun Pelajaran 2011/2012 secara empiris dapat diterima kebenarannya. Menurut penelitian yang dilakukan oleh Suryono (2009) dengan judul "Diskusi Kelompok dan Pengaruhnya terhadap Prestasi Belajar dalam Pendidikan Agama Islam di SMA Darussalam” bahwa diskusi kelompok sangat berpengaruh terhadap prestasi belajar siswa yaitu dengan adanya nilai siswa mata pelajaran PAI yang cenderung naik setelah diterapkannya metode diskusi kelompok.

Sesuai dengan latar belakang dan hasil studi pendahuluan yang dilakukan di SMAN 3 Kediri, yaitu ketika siswa berada di dalam peer groupnya ada beberapa sikap yang membuat temantemannya merasa tidak nyaman akibat kurangnya keterampilan komunikasi siswa di sekolah misalnya berbicara tanpa memikirkan perasaan teman sebayanya seperti kata-kata yang diucapkan terkadang menyinggung perasaan lawan bicaranya sehingga menimbulkan perdebatan dan kesalahpahaman, mengucapkan kata-kata kotor dan kurang sopan, sering terjadinya salah pengertian ketika mereka berkomunikasi. Masih ada yang tidak tahu bagaimana cara berkomunikasi yang baik dan benar. Hal ini terjadi pada siswa kelas X, di SMAN 3 Kota Kediri yaitu mereka kurang memiliki kemampuan komunikasi interpersonal yang telah disebutkan, maka peneliti merumuskan suatu judul yaitu "Pengaruh Layanan Bimbingan Kelompok Teknik Diskusi terhadap Kemampuan Komunikasi Interpersonal Siswa Kelas 
X SMAN 3 Kota Kediri Tahun Ajaran 2016/ 2017."

\section{METODE}

Penelitian ini dilakukan dengan pendekatan kuantitatif. Teknik yang digunakan dalam penelitian ini adalah Pre-Experimental Designs dengan bentuk One-Group Pretest-Posttest Design (satu kelompok pretest-posttest). Sampel yang digunakan dalam penelitian ini adalah 32 siswa dari populasi 200 siswa pada kelas $\mathrm{X}$ di SMAN 3 Kota Kediri. Instrumen penelitian ini menggunakan skala psikologi. Analisis data dilakukan melalui analisis hipotesis deskriptif yang akan diuji dengan statistik inferensial. Tingkat kemampuan komunikasi interpersonal siswa sebelum dan sesudah diberikan perlakuan dihitung dengan $t$ test. T-test digunakan untuk mengukur pengaruh antara satu variabel bebas (independen) terhadap variabel terikat (dependen).

\section{HASIL DAN KESIMPULAN}

Dalam penelitian ini, perlakuan yang diberikan, dilaksanakan mulai tanggal 12 Mei 2017 sampai dengan 02 Juni 2017, setiap pertemuan berdurasi 30-45 menit yang diberikan kepada kelas X-MIA 2 dengan jumlah 32 siswa di SMAN 3 Kota Kediri.

Kriteria skala komunikasi interpersonal disajikan dalam tabel berikut.

Tabel 1 Kriteria Skala Komunikasi Interpersonal

\begin{tabular}{cc}
\hline Interval & Kriteria \\
\hline $76-63$ & Tinggi \\
$62-49$ & Sedang \\
$48-35$ & Rendah \\
$34-21$ & Sangat Rendah \\
\hline
\end{tabular}

Hasil pretest kemampuan komunikasi interpersonal siswa disajikan dalam tabel berikut.

Tabel 2 Kemampuan Komunikasi Interpersonal Siswa sebelum Diberikan Bimbingan Kelompok Teknik Diskusi

\begin{tabular}{lccc}
\hline \multirow{2}{*}{ Kategori } & \multirow{2}{*}{ Interval } & \multicolumn{2}{c}{ Pre-test } \\
\cline { 3 - 4 } & & Frek. & Pros. (\%) \\
\hline Tinggi & $76-63$ & 11 & $34,38 \%$ \\
Sedang & $62-49$ & 20 & $62,5 \%$ \\
Rendah & $48-35$ & 1 & $3,12 \%$ \\
Sangat rendah & $34-21$ & - & - \\
\hline
\end{tabular}

Hasil sebelum diberikan bimbingan kelompok dengan teknik diskusi terhadap kemampuan komunikasi interpersonal siswa menunjukkan bahwa pada kelas interval 76-63 kategori tinggi sebanyak 11 siswa atau 34,38\%, pada kategori sedang menunjukkan pada interval 62-49 sebanyak 20 siswa atau $62,5 \%$ dan pada kategori rendah dengan interval 48-35 sebanyak satu siswa atau 3,12\%. Apabila dilihat dari hasil rata-rata skor pre-test skala tingkat kemampuan komunikasi interpersonal siswa kelas X-MIA 2 SMAN 3 Kota Kediri.

Hasil posttest kemampuan komunikasi interpersonal siswa disajikan dalam tabel berikut.

Tabel 3 Kemampuan Komunikasi Interpersonal Siswa Setelah Diberikan Bimbingan Kelompok Teknik Diskusi

\begin{tabular}{lccc}
\hline \multirow{2}{*}{ Kategori } & \multirow{2}{*}{ Interval } & \multicolumn{2}{c}{ Post-test } \\
\cline { 3 - 4 } & & Frek. & Pros. (\%) \\
\hline Tinggi & $76-63$ & 14 & $43,75 \%$ \\
Sedang & $62-49$ & 18 & $56,25 \%$ \\
Rendah & $48-35$ & - & - \\
Sangat Rendah & $34-21$ & - & - \\
\hline
\end{tabular}

Hasil post-test skala komunikasi interpersonal siswa menunjukkan pada kelas interval 76-63 dengan kategori tinggi sebanyak 14 siswa 
atau 43,75\%, pada kelas interval 62-49 sebanyak 18 siswa atau 56,25\% pada kategori sedang, dan tidak ada siswa yang berada pada interval 48-35 yaitu dengan kategori rendah dan 34-21 pada kategori sangat rendah.

Untuk mengetahui kemampuan awal serta mengetahui keseragaman antara kedua tes tersebut dan untuk memastikan kemampuan awal tersebut berbeda atau tidak maka perlu dilakukan uji homogenitas. Sebelum dilakukannya uji homogenitas, sebelumnya dilakukan uji normalitas, apabila data berdistribusi normal maka pengujian dilanjutkan dengan uji homogenitas, apabila data tidak berdistribusi normal, maka pengujian dilakukan uji statistik non-parametric.

Hasil uji normalitas dapat dilihat dalam tabel berikut.

Tabel 4 Hasil Uji Normalitas (Chi Kuadrat)

\begin{tabular}{lrr}
\multicolumn{3}{c}{ Test Statistics } \\
\hline & Pretest & \multicolumn{1}{c}{ Posttest } \\
\hline Chi-Square & $7.188^{\mathrm{a}}$ & $9.625^{\mathrm{b}}$ \\
Df & 18 & 17 \\
Asymp. Sig. & .988 & .919 \\
\hline
\end{tabular}

Menurut perhitungan program SPSS 16.0 hasil uji normalitas pre-test adalah sebesar 7,188 dengan df sebesar 18 yaitu dalam tabel Chi Kuadrat sebesar 28,869 dan nilai uji normalitas post-test sebesar 9,625 dengan df 17 yaitu sebesar 27,587. Sehingga nilai chi kuadrat yang dilambangkan dengan $\mathrm{X}^{2}$ antara $\mathrm{X}_{\text {hitung }}^{2}$ dan $\mathrm{X}_{\text {tabel }}^{2}$ lebih kecil $\mathrm{X}_{\text {hitung }}^{2}$ daripada $\mathrm{X}_{\text {tabel. }}^{2}$ Hal ini menunjukkan bahwa data yang diambil adalah berdistribusi normal.

Selanjutnya adalah menganalisis data dengan menggunakan uji t dengan menggunakan Paired Samples Test yang nantinya digunakan untuk menguji hipotesis pada penelitian. Untuk peng- ujian hipotesis dikerjakan dengan progam komputer SPSS 16.0 hasil t-hitung adalah sebesar $-5,274$ dan $p$-value sebesar 0,000 .

Hipotesis yaitu $\mathrm{H}_{0}$ dan $\mathrm{H}_{1}$ diuji dengan membandingkan besarnya t-hitung dengan besarnya t-tabel, dan jika besarnya p-value, maka dibandingkan dengan besarnya taraf signifikansi. Apabila $p$-value $<\alpha(0,05)$, maka ditolak, diterima. Berdasarkan kriteria, setelah dilakukan analisis data diperoleh keputusan bahwa $p$-value $(0,000)<\alpha 0,05$, maka ditolak, diterima, yaitu layanan bimbingan kelompok teknik diskusi berpengaruh terhadap kemampuan komunikasi interpersonal siswa.

Berdasarkan hasil analisis dapat diketahui bahwa dalam penelitian ini perlakuan bimbingan kelompok khususnya teknik diskusi dapat meningkatkan kemampuan komunikasi interpersonal siswa. Sehingga setelah diberikan perlakuan bimbingan kelompok teknik diskusi, kemampuan komunikasi interpersonal siswa dapat meningkat. Hal ini menunjukkan bahwa hipotesis yang telah diajukan terbukti diterima.

Diterimanya hipotesis menunjukkan bahwa teknik diskusi dalam bimbingan kelompok berpengaruh terhadap peningkatan kemampuan komunikasi interpersonal siswa kelas X-MIA 2 SMAN 3 Kota Kediri tahun ajaran 2016/2017. Pelaksanaan bimbingan kelompok teknik diskusi akan sangat mudah dilakukan oleh siswa dalam berbagai kegiatan, mulai dari pembelajaran di dalam kelas maupun kegiatan di luar kelas. Teknik diskusi dapat dilakukan kapan pun untuk dapat lebih aktif, dan berani mengutarakan pendapatnya dalam situasi apapun.

Berdasarkan hasil analisis data tentang penggunaan bimbingan kelompok teknik diskusi terhadap peningkatan kemampuan komunikasi interpersonal siswa diperoleh hasil yang positif sehingga bisa ditarik kesimpulan bahwa penggu- 
naan teknik diskusi berpengaruh terhadap kemampuan komunikasi interpersonal siswa.

Berdasarkan hasil penelitian yang telah dilakukan, siswa yang memiliki kemampuan komunikasi interpersonal sebagai berikut.

1. Kriteria rendah terdapat seorang siswa yaitu MH dengan nilai pre-test terendah yaitu 47. Kemudian setelah diberikan perlakuan yaitu bimbingan kelompok teknik diskusi, diukur dengan post-test mendapatkan nilai 51 dan meningkat kemampuannya menjadi sedang. Selama kegiatan diskusi berlangsung, $\mathrm{MH}$ selalu berusaha aktif dalam mengikuti setiap kegiatan yang berlangsung.

2. Kriteria sedang namun batas paling bawah yaitu CD yaitu dengan nilai 49 sedangkan nilai post-test-nya adalah 54, sehingga terdapat peningkatan setelah diadakannya bimbingan kelompok. Selama diskusi berlangsung CD kurang begitu aktif, namun pada kegiatan terakhir CD baru menunjukkan keaktifannya.

3. Kriteria sedang dengan nilai sedikit yaitu NL dengan nilai 52 pada nilai pretest dan 56 pada nilai posttes-nya. Hal ini menunjukkan bahwa dalam kegiatan diskusi dia pro-aktif dalam pelaksanaan diskusi.

4. Kriteria sedang yaitu DAW dengan nilai pretest 51 dan 52 pada nilai posttest. Nilai antara pretest dan juga posttest mengalami peningkatan meskipun sedikit. Dalam kegiatan DAW kurang begitu memperhatikan dan ikut serta dalam setiap tahap diskusi.

Berdasarkan penelitian yang telah dilakukan oleh peneliti di SMAN 3 Kota Kediri yang dimulai dari pengumpulan data, pemberian perlakuan, dan analisis data, hasil penelitian menunjukkan bahwa:

1. Pelaksanaan bimbingan kelompok teknik diskusi kelompok di SMAN 3 Kota Kediri de- ngan tiga (3) kali pertemuan, yaitu pada pertemuan pertama mengisi skala psikologis komunikasi interpersonal, setelah itu pembentukan kelompok. Pertemuan kedua, kelompok yang telah terbentuk mendiskusikan tema yang telah dibagi pada pertemuan sebelumnya, dan pertemuan ketiga mendiskusikan hasil diskusi kelompok di depan kelas dan evaluasi dan sharing mengenai kegiatan diskusi yang telah dilaksanakan. Selanjutnya seluruh siswa mengisi skala psikologi (post-test) yang sama seperti sebelum dilakukan kegiatan diskusi.

2. Siswa kelas X-MIA 2 SMAN 3 Kota Kediri sebelum diberikan bimbingan kelompok dengan teknik diskusi mayoritas memiliki kemampuan komunikasi yang rendah dan sedang.

3. Berdasarkan hasil perhitungan diperoleh diperoleh keputusan bahwa p-value $(0,000)$ $<\alpha(0,05)$, maka ditolak, diterima, yaitu layanan bimbingan kelompok teknik diskusi berpengaruh terhadap kemampuan komunikasi interpersonal siswa.

Berdasarkan hasil penelitian yang telah dikemukakan, maka saran yang dapat peneliti berikan adalah sebagai berikut.

1. Bagi guru

Sebaiknya guru menerapkan teknik diskusi dalam model pembelajarannya agar lebih mudah bagi siswa untuk saling berinteraksi dan bertukar pendapat. Selain penggunaan teknik diskusi dikemas dengan sekreatif dan semenarik mungkin agar siswa tertarik dan tidak merasa bosan dan tentunya dengan topik yang menarik pula.

2. Bagi siswa

Hendaknya dalam penerapan bimbingan kelompok teknik diskusi, siswa lebih aktif de- 
ngan sendirinya tanpa ada pihak lain yang harus menyuruh untuk aktif berkomunikasi.

3. Bagi peneliti

Hendaknya lebih kreatif dalam memberikan layanan bimbingan kelompok teknik diskusi, sehingga keadaan kelas bisa kondusif dan tertib.

\section{DAFTAR PUSTAKA}

Aminudin, Djoni. 2012. Meningkatkan Komunikasi Interpersonal Siswa Melalui Bimbingan Teman Sebaya. (Online), tersedia: repository.upi.edu.

Arikunto, S. 2013. Dasar-Dasar Evaluasi Pendidikan. Edisi 2. Jakarta: PT. Bumi Aksara.

Ghozali Imam. 2011. Aplikasi Analisis Multivariate dengan Program IBM SPSS 20.0. Semarang: Badan Penerbit Universitas Diponegoro.

Jannah. 2014. Metode Diskusi (online), tersedia: http://digilib.uinsby.ac.id.htm, diunduh 20 Oktober 2016.

Mardiyati, S. 2011. Bimbingan Belajar Teknik Diskusi untuk Meningkatkan Keberanian Mengemukakan Pendapat di Dalam Kelas. FKIP. UNS.

Prayitno dan Amti, E. 2008. Dasar-Dasar Bimbingan dan Konseling. Jakarta: Rineka Cipta.

Rahmat. 2013. Keefektifan Layanan Bimbingan Kelompok dengan Teknik Diskusi untuk Meningkatkan Komunikasi antar-Pribadi dengan Teman Sebaya pada Siswa. (Online), tersedia: http://perpustakaan.uns.ac. id.htm, diunduh 17 Mei 2016.

Ramadan. 2013. Penerimaan Perkembangan Fisik dengan Kematangan Emosi pada Remaja Awal. Repository UPI.

Romlah, T. 2001. Teori dan Praktik Bimbingan Kelompok. Malang: Universitas Negeri Malang.
Sari, E. 2008. Efektifitas Metode Diskusi dalam Pembelajaran Biologi Kelas X MA Uswatun Hasanah Semarang. FT. Semarang.

Setiawan. 2014. Layanan Bimbingan Kelompok dengan Teknik Diskusi Kelompok dalam Konteks Persahabatan untuk Meningkatkan Komunikasi Interpersonal Remaja di Panti Asuhan Al-Ittihad Semowo. Skripsi Dipublikasikan. Salatiga: Universitas Kristen Satya Wacana.

Sulistyanto, D. 2014. Upaya Meningkatkan Komunikasi Antar-Pribadi Melalui Layanan Penguasaan Konten dengan Metode Kegiatan Kelompok dan Diskusi Kelompok Pada Siswa Kelas VIII F SMP 5 Semarang. FIP. UNNES.

Sugiyono. 2013. Metode Penelitian Kuantitatif, Kualitatif, dan RひDD. Bandung: Alfabeta.

Sujarwo. 2008. Konseling Teman Sebaya (Peer Counseling) untuk Mengembangkan Resiliensi Remaja. (Online), tersedia: http:// jurnal.upi.htm, diunduh 15 Mei 2016.

Suryono. 2009. Diskusi Kelompok dan Pengaruhnya terhadap Prestasi Belajar dalam Pendidikan Agama Islam di SMA Darussalam.

Tohirin. 2007. Bimbingan Konseling di Sekolah dan Madrasah. Jakarta: Raja Grafindo Persada.

Utomo, H.B. 2014. Hand Out Perkembangan Individu. FKIP. UNP Kediri.

Wicaksono, G. 2013. Penerapan Teknik Bermain Peran Dalam Bimbingan Kelompok Untuk Meningkatkan Kemampuan Komunikasi Interpersonal Siswa Kelas X Multimedia SMK IKIP Surabaya. Journal Mahasiswa Bimbingan dan Konseling. (Online), tersedia: http://www.e-journal.unesa.htm, diunduh 11 April 2016.

Winkel, W.S., Sri Hastuti. 2007. Bimbingan dan Konseling di Institusi Pendidikan. Yogyakarta: Media Abadi. 